Leticia Flores Farfán

\title{
Del desgarro originario o sobre la insoportable levedad del ser en la tragedia griega
}

El único «sen» del que disponemos, según afirma Nietzsche en el Crepúsculo de los ídolos, ${ }^{1}$ es aquel que hemos recibido en la transmisión histórica de las fabulaciones. Cada fabulación es un relato «mythos», una articulación significativa, una apuesta de intervención en donde los hombres gestionan lo real, lo que tiene y lo que no tiene sentido, el rostro de su yo y de su mundo. Y ello es así porque la existencia humana, como afirma Bataille, ${ }^{2}$ se funda en la condición de exilio, de expulsión de ese transcurrir indistinto que caracteriza a los animales, y se entreteje en la palabra como apuesta/interrogación infinita por el sentido del sentido, por la razón de la razón como única forma de dar soporte y fundamento a cada uno de nuestros precarios sentidos y a cada una de nuestras frágiles razones. El ser del hombre se emplaza así en esa "[...] ruptura originaria [...] que deja ser, en el doble sentido de permitir la emergencia del ser y producir el ser como resto de la totalidad desgarrada". 3

1 Parágrafo 6 de "Como el «mundo verdadero" acabó convirtiéndose en una fábula”, Alianza Editorial, Madrid, 1982.

${ }^{2}$ Teoría de la religión, Taurus, Madrid, 1998, pp. 21-29.

${ }^{3}$ Patxi Lanceros, La herida trágica. El pensamiento simbólico tras Hölderlin, Nietzsche, Goya y Rilke, Anthropos, Barcelona, 1997, p. 54. 
Ejercer el «oficio de hombre» equivale, afirma Lluís Duch, en dar consistencia verbal a la realidad y al mismo ser humano. ${ }^{4} \mathrm{El}$ hombre es hombre gracias al lenguaje porque es justamente la palabra articulada la que marca la diferencia entre el hombre y el animal, como pone de relieve Hesíodo en Teogonía 584; por medio de la palabra el hombre se crea a sí mismo e inventa su mundo. El destino de los hombres, el sentido de su existencia se trama en relatos que configuran lo real como significativo y eminente con base en el vínculo simbólico que entrelaza la distancia instaurada por la ruptura originaria, por la herida constitutiva entre el sentido y el sinsentido, lo humano y lo divino, lo profano y lo sagrado. De ahí la cualidad simbólica de cada uno de nuestros relatos, pues el symbolon conlleva la creación de vínculos entre la palabra y lo inefable, entre el sentido y el sinsentido, y reconduce lo que aparece a un ser irremediablemente ausente o «imposible» de conocer directamente, porque el símbolo, como afirma Durand, ${ }^{5}$ pertenece al universo de la parábola dando al prefijo de este término toda la fuerza que tiene en griego: para= «que no alcanza». Esta inagotabilidad delinea la frágil condición del vínculo simbólico pues, si bien éste configura lo real por su vehemencia significativa, queda excedido por esa inefabilidad «que no alcanza» y por la que no logra nunca encarnar una perfecta adecuación, suturar de manera definitiva la herida o ruptura originaria habilitando así el emplazamiento inagotable de múltiples configuraciones significativas en donde se arma de manera distinta el sentido secreto, la epifanía del misterio. ${ }^{6}$

El devenir histórico no es un acontecer unitario en donde se va desplegando sucesivamente una «naturaleza humana», sino un transcurrir plagado de universos simbólicos, de imaginarios

${ }^{4}$ Mito, interpretación y cultura, Herder, Barcelona, 1998, p. 458.

${ }^{5}$ La imaginación simbólica, Amorrortu, Buenos Aires, 1971, pp. 14-15.

${ }^{6}$ Ibidem, pp. 22-23. 
sociales, ${ }^{7}$ a cuya comprensión sólo podemos acceder si no pretendemos hacer abstracción de todo contexto y valor de uso de las palabras. ${ }^{8}$ Todas las fabulaciones, relatos significativos, constelaciones de sentido se arman ante la ausencia, ante esa totalidad perdida, y lo hacen siempre como lenguaje ontológicamente cualificado, es decir, como cultura. Por ello, en estas páginas intentaremos abrimos a la comprensión de la «experiencia trágica», de esa experiencia que se emplaza en un pathos cuyos rasgos más propios, como afirma Patxi Lanceros, ${ }^{9}$ se concretan en la distancia de los dioses, la omnipotencia del destino (Moira) y el derecho de los muertos, acercándonos a la cultura que la significa y asumiendo que toda apuesta de significación se articula en la confrontación con la herida, con el enigma que atraviesa la esfera de lo humano.

\section{$*$}

Como se afirma en la Odisea 1,338 , los temas de los relatos épicos son «Las acciones de los hombres y los dioses». En el mundo de Homero, entre lo divino y lo humano se establecen estrechas relaciones de amor, de rechazo, de complicidad, de ternura. Dioses y hombres habitan el mundo, pueblan su territorio, dibujan su geografía. Por ello, las polifacéticas potencias divinas que habitan el Olimpo dejan siempre su rastro en la morada de esos mortales que «semejantes a las hojas, unas ve-

${ }^{7}$ Asumiendo la carácterización que realiza Cornelius Castoriadis en La institución imaginaria de la sociedad, tomo 1, Tusquets, Barcelona, 1983, p. 10, el imaginario " [...] no es imagen de. Es creación incesante y esencial indeterminada (social-histórica y psíquica) de figuras-formas-imágenes, a partir de las cuales solamente puede tratarse de 'alguna cosa'. Lo que llamamos 'realidad' y 'racionalidad' son obras de ello".

8 Cfr. Jacques Derrida, La deconstrucción en las fronteras de la filosofía, Paidós/ICE-UAB, Barcelona, 1989, p. 84.

${ }^{9}$ Op. cit., pp. 116-117. 
ces se hallan florecientes, cuando comen el fruto de la tierra, y otras veces se consumen exánimes». ${ }^{10}$

El mundo homérico está saturado de dioses, de fuerzas y figuras que constantemente se hacen presentes aunque siempre de manera furtiva, obnubilada, traslúcida, y bajo la apariencia de mil disfraces y múltiples formas:

[...] los dioses tienen un cuerpo que, a voluntad, pueden volver (o dejar) totalmente invisible a los ojos de los mortales sin que por ello deje de ser un cuerpo. La visibilidad que definía la naturaleza del cuerpo humano en tanto que presenta necesariamente una forma (eidós), una ençarnación coloreada (chroié), una apariencia exterior de piel (chrós), toma para los dioses un sentido completamente diferente: la divinidad, para manifestar su presencia, escoge hacerse visible no tanto bajo la forma de su cuerpo como bajo la apariencia de un cuerpo. ${ }^{11}$

La presencia de los dioses se delata por la majestuosidad de sus huellas; ninguna forma individual puede acoger la infinita potencia, la vitalidad imperecedera, que circula lo divino. Poseidón se transfigura en el adivino Calcas y habla para infundir vigor y confianza a los Ayax; ${ }^{12}$ pero el divino, aun bajo la envoltura de un cuerpo visible, no puede ocultar su magnífica condición, su desconcertante alteridad, pues, «como el gavilán de ligeras alas se arroja desde altísima y abrupta peña, enderezando el vuelo a la llanura para perseguir a un ave», ${ }^{13}$ devela así su naturaleza etérea e incorpórea.

10 Il., XXI, 460-465.

11 J.P. Vernant, "Cuerpo oscuro, cuerpo resplandeciente" en M. Feher; R. Naddaff; N. Tazi (eds.), Fragmentos para una Historia del cuerpo humano, Taurus, Madrid, 1990, p. 34.

${ }^{12}$ Il., XIII, 59-61.

${ }^{13}$ Il., XIII, 59. 
Los dioses homéricos, preocupados por los débiles mortales, se implican y envuelven en los aconteceres humanos dejando huellas materiales y perceptibles de su tránsito: Afrodita salva a Paris del golpe de Menelao haciéndolo desaparecer del campo de batalla bajo la única visibilidad de un fuego $;{ }^{14}$ Apolo enfurecido por la humillación ejercida por Agamenón contra uno de sus sacerdotes, baja del Olimpo para vengarse y accede a ser protagonista de la cruenta guerra de Troya ${ }^{15}$ Los olímpicos, pletóricos de deseos, de amores, de iras y pasiones, despiertan cada día en la Aurora de la mañana, con alguna intención, algún proyecto o deseo que dejarán inscrito en el acontecer de los mortales, bien ordenándolos desde las alturas o bien por intromisión directa.

Los dioses permean todo y no desconocen ni retroceden ante forma alguna de injerencia: irrumpen en lo onírico, se invisten en el disfraz de cualquier cuerpo, persuaden ${ }^{16}$ pensamientos, afectos y decisiones a través del consejo, la sugerencia o el mandato. Lo divino se inscribe en la raíz misma del actuar de los mortales porque, tal y como se nos cuenta en el inicio del canto undécimo de la Ilíada, si bien es Agamenón quien da la orden de armarse, tras su grito se encuentra el de la diosa Discordia quien «dio un elevado y terrible chillido estridente e infundió gran brío a cada uno de los aqueos en el corazón, para combatir y luchar con denuedo». ${ }^{17}$ Todos los héroes son desenfrenadamente pasionales; en su extraordinaria fuerza y coraje, belleza y resistencia, manifiestan la condición pletórica de su desmesura. Y los dioses están ahí, a su lado, para ayudarlos a no sucumbir ante los violentos impulsos que

$$
\begin{aligned}
& 14 \text { Il., III, 373-382. } \\
& 15 \text { Il., I, 44-45. }
\end{aligned}
$$

16 Como podemos observar en la acción impulsiva de Pándoro que, siguiendo el consejo de Laódoco (Atenea), dispara a Menelao y con ello rompe el pacto sagrado entre aqueos y troyanos. Il., IV, 85 ss.

${ }^{17} \mathrm{Il} ., 10-12$. 
los arrebatan, para empujarlos sin ceguera hacia la batalla, para otorgarles habilidad en la ejecución, para encender la llama de gloria que otorga el valor guerrero o bien, por virtud de un humor cambiante, para engañar a un hombre o torcerle su voluntad. Heroísmo y voluntad divina se entrelazan porque "[...] lo real resplandece realmente cuando su esplendor se duplica, cuando al brazo del héroe responde el brazo del dios que lo acompaña, cuando dos escenas, una visible y la otra invisible puesto que es deslumbrante, se acoplan entre sí y todas las junturas se duplican". ${ }^{18}$

Sin embargo, este engarce destinal entre dioses y hombres comienza a sufrir menoscabo en el momento mismo en que Hesíodo canta en la Teogonía una genealogía de los dioses separada de la historia de los mortales, que será motivo del canto de Los trabajos y los días. Los morbosos y entrometidos dioses del relato homérico comienzan a dejar la escena. Dioses y hombres configuran dos juegos de aconteceres cuyas rutas, si bien se tocan, ya no se encuentran fuertemente entrelazadas. Los divinos inmortales acceden a un orden feliz, sosegado y pacífico, después de que - vencidas violentas vicisitudes-, Zeus, desde la alta cumbre de la tierra urania y por obra de su indiscutible autoridad, ordena la ciudad divina y conforma un Panteón olímpico unificado. Zeus se transfigura en la Realeza misma en el momento en que deja de ser uno más entre los dioses. ${ }^{19} \mathrm{~A}$ par-

18 Roberto Calasso, Las bodas de Cadmos y Harmonía, Anagrama, Barcelona, 1992, p. 306.

19 De aquí la comparación que sugiere Cornford, en Principium sapientiae. Los orígenes del pensamiento filosófico, La balsa de Medusa/Visor, Madrid, 1987, entre el mito del Zeus cretense y el triunfo de Marduk en el Enuma Elish babilónico. Asimismo, sostiene Detienne en Los maestros de verdad en la Grecia arcaica, Taurus, Madrid, 1981, el doble registro de la poesía adquiere significación al ponerse en contacto con la conformación palatina de la sociedad micénica: en ella, el rey poseía un carácter divino, comparable al que se le atribuía en las teogonías orientales. Como lo ha señalado Cornford, el papel del poeta era el de ser un "funcionario de la soberanía". Las monarquías, al ubicar junto al rey al jefe del Laos, establecen una primacía de la función guerrera. Pero este último 
tir de aquí, los divinos comenzarán a conformarse en figuras individuales bien delimitadas y habitarán una escena existencial decididamente alejada del dramatismo y agitación que invadía a los dioses homéricos. La palabra divina se engarza con la justicia «diké» haciendo que los dioses celestes que viven en la luz constante del éter, con su personalidad y figura concretas, sus funciones articuladas unas en otras, ${ }^{20}$ equilibren y ajusten sus poderes bajo la autoridad inquebrantable de Zeus. La embriaguez de una diké que todo lo invade hace caer en el olvido las cruentas guerras, las terribles pasiones que azotaban a dioses y mortales.

La genealogía de los dioses sitúa el tiempo de la acción en el agitado pasado del origen. El hoy de los dioses se narra a partir del triunfo de la justicia y el orden en el Olimpo. El acontecer divino, por tanto, deja de insertarse en violentos conflictos y transita en un existir apacible que se deleita con los cantos de las Musas que entonan el recuerdo de sus pasadas hazañas. ${ }^{21}$

Así, el mismo canto que ocasionalmente distrae a los desventurados hombres, halaga sin cesar el corazón de Zeus. Esa misma armonía que sirve de alivio a los mortales en los momentos de luto, sumerge a los dioses en una contemplación continua de su propia imagen e historia. Gozar y sentir la plenitud en sí mismos y vivir en una perenne satisfacción: ¿qué otra cosa nueva, mejor, diferente, podrían desear estos dioses melómanos?"22

acontecer no aparece directamente atestiguado en la civilización micénica; la referencia agonal más certera la constituye Esparta y ante ésta, el poeta se instituye como cantor de alabanza y desaprobación de los episodios de armas. En ellos, el poeta recurre a la referencia de los árbitros - cetro en mano-comunicando sus decisiones en el ágora y marca así una distancia con el periodo micénico pues en éste la escritura de Lineal B en manos de lo escribas, aunque elitista y complicada, posibilitaba el control y reproducción de la sociedad.

20 J. P. Vernant, “Cuerpo oscuro...” en op. cit., p. 41.

21 Hesíodo, Teogonía, 35 ss.

22 Giulia Sissa y Marcel Detienne, La vida cotidiana de los dioses griegos, 
Lejos estamos ya de poder entrever a Hefesto y a Tetis afligidos por el dolor como los presenta Homero en la Ilíada ${ }^{23}$ aún más lejos estamos de concebir a los dioses preocupados y atareados por la pesadumbre y miseria de los destinos humanos. Cuando los dioses se replegaron a la paz sosegada del Olimpo, la voz de los divinos dejó de escucharse nítida y claramente en el mundo de los mortales quedando solamente audible el rumor de su elocuente silencio. La unidad cómplice entre dioses y hombres quedó rota y el fuerte entramado entre voluntad humana y divina, las pretendidas raíces sólidas en que se asentaban el pensamiento y lo real, la persistente y tenaz presencia de los dioses de Homero comenzaron a sufrir menoscabo. Los dioses olímpicos devinieron invisibles, incógnitos, lejanos; su actuar ya no acompasaría más al de los débiles mortales, ya no lucharían con los hombres o contra ellos, ya no se involucrarían en los amores, las pasiones y los avatares humanos de manera directa e inmediata. Los dioses se repliegan en la inaccesible cumbre y la experiencia trágica se abre camino; con ella se hace patente la precariedad de la palabra humana, la deriva significativa que el quiebre destinal entre hombres y dioses provoca, y la necesidad de acoger nuestro actuar y nuestro decir a esa primera constatación. ${ }^{24}$

Y esta creciente desaturación del mundo de la acción de los dioses va dando paso al "hablar de lo profundo", al Enigma, pieza principal de la tragedia ática. El Enigma comparece como un fondo tenebroso, un decir oscuro, un algo inexplicable y perturbador, una tensión entre lo que puede saberse y lo que se hunde en la penumbra del sinsentido porque la configuración

Planeta, Madrid, 1991, p. 43. Se señala también que esta idea de lo divino como placer reflexivo, adelanta la idea aristotélica del Motor inmóvil cuya única actividad es la de pensarse a sí mismo como tal pensamiento, y la del tiempo divino como un eterno presente.

${ }^{23}$ Il., 588; XIX, 8.

24 Patxi Lanceros, op. cit., p. 119. 
del mundo y sus legalidades ya no se encuentra engarzada con esa palabra divina del relato épico que le daba orientación y sentido, sino que ahora es vista como producto de un desgarro ontológico, de una herida constitutiva, de una fisura o separación originaria de la totalidad primigenia que, como apuesta de sentido, se trama en la articulación del vínculo simbólico entre aquellos fragmentos escindidos de la totalidad rota. El ser accede a la existencia por la ruptura originaria de la totalidad indiferenciada y se estatuye absoluto, pero no en el sentido filosófico de necesario e imperturbable, sino en el mítico de absuelto, es decir, como fragmento o resto de la totalidad escindida y desgarrada. Se da así el salto a escena de esa experiencia trágica que nos hace vivir, tensa y polémicamente, entre memoria y olvido, presencia y ausencia, definición y plegaria.

Ante la retirada de los dioses, los hombres dirigen la interrogación del sentido de su existencia a los oráculos, pero con cada respuesta se abren nuevas preguntas, con cada resolución se manifiesta el fondo enigmático en el que se articula topoló-gicamente el sentido pues "El oráculo mismo no es ya una orden, sino una palabra particularmente solemne cuya ambigüedad es fundamental" 25 porque "[...] TAL COMO EL SEÑOR, CUYO TEMPLO DIVINATORIO ESTÁ EN DELFOS, como nos lo hizo saber Heráclito, NI DICE NI OCULTA, SINO QUE DA SEÑAS". ${ }^{26}$ El Oráculo no oculta su juego porque no es un jugador, sino el código que regula el juego y según el cual actúan los jugadores. ${ }^{27} \mathrm{O}$, en palabras de Patxi Lance$\operatorname{ros}^{28}$

${ }^{25} \mathrm{P}$. Vidal-Naquet, Formas de pensamiento y formas de sociedad en el mundo griego. El cazador negro, Península, Barcelona, 1983, p. 299.

${ }^{26}$ Fr. 37 en Agustín García Calvo, Razón Común. Edición crítica, ordenación, traducción y comentario de los restos del libro de Heráclito, Lucina, Madrid, 1985, p. 114.

27 Cfr. J.F. Lyotard, ¿Por qué filosofar?, Paidós/I.C.E.-U.A.B., Barcelona, 1989 , p. 108.

28 "El silencio es resto" en Letras de Deusto, vol. 22, núm. 52, enero-febrero 1992, p. 137. 
El silencio no es el objeto del que se habla sino el espacio en que se habita, el desgarrón, el profundo abismo, la sima sobrecogedora en la que duermen el texto, el verbo y la memoria. El silencio es el preámbulo de la palabra, su condición de posibilidad, el grado cero del significado y simultáneamente la totalidad replegada del sentido.

El silencio es el repliegue divino, el abismo inaccesible que entreteje toda palabra, todo sentido. El repliegue de los dioses convierte a la existencia humana en una deriva, en una interpretación interminable de una palabra divina que se manifiesta oblicua y esquiva. Ya no hay posibilidad para los hombres de emitir una palabra sensata porque no hay signo que indique el sentido que debe pronunciarse, es decir, no hay garantía divina de que lo que se dice pueda asumirse como la palabra verdadera y definitiva; la presencia se emplaza en un fondo de ausencia y la interrogación no tiene más respuesta que el enigma que reta persistentemente a ser descifrado. El silencio es el Caos y míticamente éste "[...] no es el mundo preexistente en estado caótico. (No es la materia indiferenciada, no es el Espíritu diferenciador). No es una realidad; no es más que una denominación simbólica. Es el caos que el espíritu humano encuentra cuando intenta explicar el origen del mundo. $\mathrm{El}$ «Caos» simboliza el fiasco del espíritu humano ante el misterio de la existencia [...] El símbolo quiere decir: lo que está «al comienzo» es caótico (misterioso) para el espíritu humano y su esfuerzo de explicación".29.

Este desgarro ontológico que atraviesa la subjetividad humana traduce una falta, una imposibilidad de respuesta a la inquietante pregunta sobre la razón de ser de nuestro ser, que hace de la identidad una instancia frágil y difusa.

29 Paul Diel, El simbolismo en la mitología griega [Prólogo de Gastón Bachelard], Idea Universitaria, 1998, p. 98. 
Cuando, a la manera de Edipo, quiere llevar hasta el final la investigación sobre lo que es, el hombre se descubre a sí mismo como enigmático, sin consistencia ni dominio que le sea propio, sin punto de engarce fijo, sin esencia definida, oscilando entre igual a un dios e igual a nada. Su verdadera grandeza consiste en eso mismo que expresa su naturaleza de enigma: la interrogación. ${ }^{30}$

La identidad particular, así como la colectiva, no logra dibujar con precisión sus contornos, no logra erigirse más que bajo una certeza frágil, porque se encuentra permanentemente amenazada por el silencio que la funda o soporta; el rostro de los hombres tendrá que armarse borrosamente sobre el fondo del misterio, en la red indescifrable de la palabra divina, bajo una pluralidad de máscaras y personajes que se mueven en una escena existencial de la que el hombre no es plenamente el dueño. ${ }^{31}$ La conciencia accede al desgarro originario, a la herida constitutiva que la funda, se pone cara a cara ante el carácter ambivalente que la conforma y confronta ineluctablemente la imposibilidad de resolución del conflicto que la sostiene.

Con la retirada de los dioses, todos los afectos y aflicciones, pasiones y deseos se van haciendo paulatinamente humanos, pero sin lograr separarse por completo de la esfera divina porque " [...] entre los trágicos, la acción humana no tiene en sí bastante fuerza para prescindir del poder de los dioses, ni suficiente autonomía para concebirse plenamente al margen de ellos". ${ }^{32} \mathrm{El}$ actuar del héroe trágico se juega por entero en un espacio de vida mensurable, discontinuo y limitado, perma-

30 J. P. Vernant y P. Vidal-Naquet, Mito y tragedia en la Grecia antigua, tomo I, Taurus, Madrid, 1987, pp. 132-133.

${ }^{31}$ Un análisis detenido de las diferencias entre Sófocles, Esquilo y Eurípides en cuanto al carácter trágico se encuentra en Carlos García Gual, "Destino y libertad del héroe trágico" en Figuras helénicas y géneros literarios, Mondadori, Madrid, 1991, pp. 22-31.

32 J. P. Vernant y P. Vidal-Naquet, op. cit., p. 39. 
nentemente presionado tanto por la legalidad de los dioses como por la ley no escrita de los muertos. Dioses y muertos se manifiestan como el límite del mundo de la vida en un doble sentido: primero, porque la vida se juega en los límites del nacimiento y la muerte, y, segundo, porque la validez de las apuestas de sentido de la vida misma se encuentran, al límite, en constante tensión con el inasible fondo abismal que las soporta.

Instalado en su personaje de descifrador de enigmas y de rey justiciero, convencido de que los dioses le inspiran, proclamándose hijo de la Tyche, de la Buena Fortuna, ¿cómo podría comprender Edipo que se refería a sí mismo ese enigma, cuyo sentido no adivinará más que descubriendo ser lo contrario de lo que creía, no el hijo de la Tyche, sino su víctima, no el justiciero, sino el criminal, no el rey salvador de su ciudad, sino la abominable mácula por la que está pereciendo $?^{33}$

El héroe aventura su acción en una apuesta de sentido, en una demarcación limitada en el terreno de lo conocido, pero internándose en ese mismo movimiento en un terreno impenetrable e incomprensible, porque la respuesta que los dioses le entregan cuando, suplicante, lanza su apelación hacia ellos, es siempre equívoca y ambigua:

Edipo aparece como el modelo perfecto de la revelación trágica. Edipo, el rey con ojos reventados, es víctima de una auténtica jugarreta «celestial». La divinidad le ha puesto un cepo en su destino. Realiza los crímenes más odiosos: mata a su padre, se casa con su madre, iy todo sin saberlo, ciegamente, antes de cegarse a sí mismo! ${ }^{34}$

33 Ibidem, p. 40.

${ }^{34}$ François Laplantine, El filósofo y la violencia, EDAF, Madrid, 1977, p. 77. 
La experiencia trágica y la consecuente fuerza del desgarro ontológico que su aparecer pone en juego, inscriben los avatares del hombre en un intento inagotable de reconciliación, de sutura de la herida constitutiva, pero sin victoria definitiva pues la palabra humana acogerá la escisión originaria pero sin redimirla, sin mayor certeza que las efímeras seguridades que se arman en colisión y complicidad con el sinsentido de la muerte.

La muerte no se reduce solamente al acabamiento de la vida en un sentido físico, sino que es el límite en donde estalla la necesariedad del sentido mismo y se revela tanto la fragilidad de nuestra existencia como la debilidad de sus precarias certezas. La muerte aparece como ese absolutamente otro cuya radical alteridad no hace más que poner en tela de juicio el carácter necesario de todas las coordenadas que configuran el mundo de la vida.

Gorgo señala la frontera del mundo de los muertos. Penetrar allí bajo su mirada significa transformarse, a imagen de Gorgo, en lo que son los muertos, cabezas vacías y sin fuerza, cabezas cubiertas de noche. Los artistas griegos expresan formalmente esta alteridad radical haciéndola visible a la mirada humana a través de la monstruosidad basada en el oscurecimiento sistemático de todas las categorías que distingue el mundo organizado y que, en ese rostro, se mezclan e interfieren. ${ }^{35}$

Vida y muerte se juegan en una tensión inconciliable porque la muerte se erige como el enigma mismo y, en tanto enigma, la razón no alcanza a dar cuenta de él; experiencia del extremo, experiencia en el extremo, lo trágico convoca al mito, al tejido simbólico cuyo signo encarna la inadecuación con el significado inefable e invisible al que remite.

35 J. P. Vernant y P. Vidal-Naquet, Mito y tragedia en la Grecia antigua, tomo 2, Taurus, Madrid, 1989, p. 33. 
En lo trágico, todas las decisiones de los «semejantes a hojas», ${ }^{36}$ como calificaba Homero a los hombres, dejarán de arroparse en la certidumbre de un destino manifiesto y se emplazarán en un fondo de abandono y silencio, en un destino oscuro e incomprensible, cantado ansiosa y persistentemente por el coro ${ }^{37}$ emplazado en la orchestra, "[...] porque los griegos solían hablar de cualquier desastre personal inexplicable como parte de su 'sino' o de su 'hado', queriendo decir simplemente que no podían comprender por qué ocurría, pero que, puesto que había ocurrido, evidentemente 'tenía que ser'" 38

En el relato trágico se realiza un importante desplazamiento con respecto a la narrativa épica anterior pues, como argumenta Robin Osborne, ${ }^{39}$ Sófocles matiza la preeminencia de «los infaustos designios divinos» que impregnan la historia de Edipo que cuenta Ulises en Odise $^{40}$ y articula la acción en una tensa y compleja suma de decisiones humanas y designios divinos que permiten que el Edipo de Sófocles pueda afirmar "Apolo fue quien hizo cumplirse estos terribles sufrimientos míos. Pero nadie, sino yo mismo, desdichado, me golpeo con mi propia mano". ${ }^{41}$ En la acción trágica, como afirma Carlos García Gual, ${ }^{42}$ no hay posibilidad de hablar de una verdadera

36 Cfr. supra nota 10.

37 "Por un lado, el coro [...] personaje colectivo encarnado por un colegio de ciudadanos; por otro lado, el personaje trágico, representado por un actor profesional, y al que su máscara individualizaba en relación al grupo anónimo del coro. Esta individualización no hace en modo alguno del portador de la máscara un sujeto psicológico, una «persona» individual. Al contrario, la máscara integra al personaje trágico en una categoría social y religiosa muy definida: la del héroe". J. P. Vernant y P. Vidal-Naquet, Mito y tragedia en la Grecia antigua, tomo 2, p. 16.

38 Dodds, Los griegos y lo irracional, Alianza, Madrid, 1985, p. 20 [Alianza Universidad, 268].

39 "Epílogo" en Robin Osborne (ed.), La Grecia Clásica 500-323 a.C. [tr. Gonzalo G. Djembé], Crítica, Barcelona, 2002, pp. 247-250.

40 Odisea XI, 271-280.

${ }^{41}$ ER 1331-1334.

42 Op. cit., pp. 27-31. 
fatalidad, de una determinación pura, porque la divinidad no fuerza a tomar determinada actitud, a lo más, la sugiere. Los dioses asisten impasibles al desastre pero no lo determinan, lo constituyen en tanto que son el Enigma mismo. La acción trágica y la responsabilidad que conlleva se tejen en una compleja red de decisiones atravesada, a su vez, por una ignorancia particular «ágnoia» que nos obliga a aceptar la extraña conjunción entre designio divino y decisión humana.

Hay, por otra parte, un segundo desplazamiento de vital importancia señalado por Osborne,,$^{43}$ a saber, el de que la narración trágica hace que las decisiones de sus héroes vayan más allá del campo ético personal, en tanto que la acción repercute en toda la comunidad y adquiere así un carácter político que no permite reducirla a ningún destino individual. La explicación homérica de que algo «había sido tramado por los maliciosos dioses», afirma Osborne,${ }^{44}$ ya no convencía a los ciudadanos atenienses que tomaron el destino en sus manos. Por ello, la escenificación trágica por la que veló la polis ateniense de los siglos v y IV se emplazó como un espacio público en donde presentar a la valoración de todos, los mismos problemas que se ventilaban y debatían en la Asamblea ciudadana. ${ }^{45}$

${ }^{43}$ Op. cit., pp. 248-250. Afirma Osborne que "Sófocles no sólo llama la atención sobre Edipo y Yocasta, sino también sobre los esclavos que debían haber abandonado al Edipo recién nacido y en cambio procuraron su adopción por la familia real de Corinto. Y todo ello queda coronado por una dimensión política: Sófocles no sólo destaca que Edipo es un rey, sino varios detalles concretos de su forma de gobernar. En la Odisea, la historia de Edipo es un ejemplo lejano de cómo algunos mortales tienen la desgracia de sucumbir a las maquinaciones de los dioses; en la obra de Sófocles, la acción ha pasado a desarrollarse en una ciudad con un aire que resultaba familiar para los atenienses (aunque no se trata en ningún caso de una réplica de Atenas), y los personajes se han convertido en figuras cargadas de rasgos humanos también familiares".

44 Ibidem, p. 249.

${ }^{45}$ Francisco Rodríguez Adrados, Democracia y Literatura en la Atenas clásica, Alianza, Madrid, 1997, pp. 16-18 [Alianza Universidad, 873]. 
Las tragedias se representaban en un marco ciudadano, el teatro de Dioniso al pie de la Acrópolis, y en unas fiestas cívicas, las dionisíacas, ante un auditorio que era toda la ciudad. La representación conservaba, en su marco festivo, muchos elementos religiosos. $Y$ es interesante subrayar que fue justamente una polis democrática como Atenas la que velaba oficialmente por esas representaciones teatrales. Mientras que no se preocupaba por facilitar el aprendizaje de la lectura y la escritura, es decir, de la grámmata, ni siquiera a un nivel elemental, proporcionando una enseñanza general y gratuita (como sí se hizo en la colonia panhelénica de Turios), sino que tal cosa quedaba al arbitrio y conveniencia particular de los ciudadanos, el Estado ateniense velaba por el teatro, como si éste fuera fundamento de la cultura y la sociabilidad, como algo fundamental en la paideia comunitaria. ${ }^{46}$

La experiencia trágica relatada en los mitos, las tensiones entre libertad y tiranía, entre el poder político y la ley religiosa tradicional, los conflictos provocados por el establecimiento de los límites del poder y todos los problemas que interesaban a una ciudad libre, se pusieron en escena y se sometieron a la consideración y valoración de la ciudad misma en el escenario del teatro trágico, ${ }^{47}$ en esa fiesta litúrgica anual ${ }^{48}$ en donde se

${ }^{46}$ Carlos García Gual, La Mitología. Interpretaciones del pensamiento mítico, Montesinos, Barcelona, 1989, p. 37 [Biblioteca de Divulgación Temática, 43].

47 “E] Estado proveía todos los gastos de las representaciones teatrales, en el marco de la fiesta dionisíaca, mediante el impuesto de las coregías, que recaía sobre los ciudadanos más ricos, cada año. Tamibién por encargo estatal, en el marco de las fiestas Panateneas, se recitaban los poemas homéricos. Qué extraño caso éste: el de una democracia que recupera y reclama como base educativa la rememoración de los mitos heroicos, de claro origen aristocrático, y trata de enfocarlos desde la óptica cívica, en un ambiente democrático e igualitario. La épica y la tragedia - y también la lírica coral doria - fueron no sólo formas de arte, sino también instituciones sociales con valor educativo", en idem.

48 “La fiesta en que se presenta la tragedia conserva rasgos de ritual. Está presidida por el sacerdote de Dioniso, que ocupa un asiento especial en la primera fila del auditorio, comienza con un sacrificio en el altar que está en el centro de la 
encubre y desvela la trágica condición del hombre, ${ }^{49}$ la confrontación irreductible entre sentido y sinsentido, el Otro y el Mismo, la lucha interminable entre las figuras paradigmáticas de Dioniso y Apolo. En el escenario trágico se hace patente la inasible esencia del mundo y la escenificación se asume como tal, se sabe expresión de lo irrepresentable porque lo que se pone en juego es la encarnación del supremo Destino.

El escándalo que nace del aplastamiento del héroe por el destino será cantado y representado en un espectáculo al no poder elaborarse reflexivamente. Lo que no pueden decir ni la filosofía ni la teología nos lo mostrará el espectáculo. De él nace la emoción trágica, mezcla de sorpresa y de espera, de indignación y de consentimiento. Es piedad a la vez que terror y sublimidad, pero nunca entrega. A decir verdad, la salvación no se encuentra ni dentro ni fuera de lo trágico. ${ }^{50}$

Cuando la experiencia trágica se articuló en la historia mítica, se logró que la narración sagrada hiciera patente el desgarro ontológico originario y la fragilidad de toda apuesta de significación que se levanta sobre la herida constitutiva. Con ello hizo evidente que no hay respuesta a la interrogación sobre lo que somos, que no hay forma de escapar a ese indescifrable destino inexorable de ser mortales, y habilitó un insoportable sentimiento de indefensión ante el misterio que atraviesa la esfera de lo humano que ha posibilitado interpretar la tragedia bajo un talante de fatalidad y pesimismo. Pero el vaciamiento ontológico

orchestra, delante de la escena, tiene unos orígenes en ritos sagrados (sean cuales fueran), y mantiene elementos arcaicos como las máscaras, los coros, la presencia de los dioses, etc.". Ibidem, p. 38.

49 "La tragedia era [...]la liturgia de la polis, el «auto sacramental» en que la sociedad se exaltaba a sí misma como encarnación de lo divino; no tanto de los diosecillos olímpicos cuanto del supremo Destino", en José Ma. Valverde, La literatura, Montesinos, Barcelona, 1989, pp. 78-79.

${ }^{50}$ Laplantine, op. cit., p. 82. 
que la experiencia trágica pone en juego, afirma Laplantine si-. guiendo las interpretaciones de Nietzsche y Hölderlin, nos puede llevar a comprender la contradicción más profunda que entreteje el entramado trágico, a saber, que "[...] este Otro que me domina es el Yo-mismo en un grado que conozco mal. El destino es la libertad, y la libertad es el destino. La fatalidad no se encuentra fuera del carácter del héroe, de su destino"; ;1 por ello, cuando contemplamos con serenidad el silencio del mundo, la insolencia del acontecimiento insólito, escandaloso y sin razón, podemos reconocer no sólo el hecho de la vulnerabilidad humana, sino también su eminente valor: el hombre se hace cargo de sí mismo, se apropia de la Tierra y acepta la condición de desplegar en el mundo un sin fin de apuestas de sentido que le permiten asumir, como dice Bataille, que "[...] la vida es una fiesta inmotivada: y una fiesta en todos los sentidos de la palabra, una risa, una danza, una orgía que no se subordinan nunca, un sacrificio que se burla de los fines, sean materiales o morales". 52

La experiencia trágica que se emplaza en el espacio ateniense de la época clásica se despliega como una demanda de totalidad que no encuentra respuesta satisfactoria, que no habilita la sutura definitiva entre las partes del todo desgarrado, pero articula los avatares humanos, los haceres y decires que forman la trama de la vida, en una errancia sin fin de certezas precarias y frágiles vínculos simbólicos ${ }^{53}$ que deberán resguardarse y protegerse, hacerse sagrados, para garantizar la convivencia pacífica de la ciudad y posibilitar el desarrollo pleno de los hombres.

51 Op. cit., p. 82.

52 Georges Bataille, Sobre Nietzsche [Tr. Fernando Savater], Taurus, Madrid, 1979 , p. 25.

53 Afirma Paul Ricoeur en "El simbolismo y el mal" en Finitud y culpabilidad, Taurus, Madrid, 1982, pp. 330-331, que “[...] todo símbolo es en última instancia una hierofanía, una manifestación del vínculo del hombre con lo sagrado [...] pues, el símbolo nos habla como indicador de la situación del hombre en el centro del ser en el que se mueve, existe y quiere". 
Los atenienses comprendieron que, en el alma humana, “[...] tienen una raíz única la grandeza y el egoísmo, el honor y el abuso, la inteligencia y la ceguera, el sacrificio y la parcialidad" 54 y que las «esperanzas ciegas» que Prometeo ${ }^{55}$ otorgó a los hombres como remedio para enfrentar la insoportable levedad del ser, su eminente condición mortal, abrían camino a una poderosa potencialidad creativa de apuestas humanas de significación que posibilitaría, tal vez, hacer más respirable el desgarro originario y el elocuente silencio divino.

${ }^{54}$ Francisco Rodríguez Adrados, La democracia ateniense, [adaptado por Manuel Gonzalo], Alianza, Madrid, 1975, p. 17 [Alianza Universidad, 107].

55 Esquilo, Prometeo encadenado, v. 250. 